\title{
International student mobility and the transition from higher education to work in Norway
}

\author{
Jannecke Wiers-Jenssen $^{1} \cdot$ Liv Anne Støren ${ }^{2}$
}

Published online: 27 June 2020

(C) The Author(s) 2020

\begin{abstract}
The purpose of this paper is to investigate whether international student mobility (ISM) has an impact on the transition from higher education to work. Two measures of labour market outcomes are investigated: unemployment and skills mismatch. To go beyond existing research, we analyse whether the effect of ISM on these outcomes vary by fields of study, intake grades, sociodemographic variables and more. Our analyses are based on data from the Norwegian graduate surveys time series from 2007 to 2017. After controlling for several confounding factors, we find very small differences in labour market outcomes between graduates with and without ISM experience. In comparison with field of study, immigrant background, previous labour market experience and business cycles, the effect of ISM on the examined labour market outcomes is small. Investigating whether graduates with different backgrounds benefit differently from ISM, we find evidence of moderate effect heterogeneities: Graduates with high intake grades and graduates in business and administration seem to benefit somewhat more. Regarding social origin and immigrant background, no heterogeneous effects are found. Contrary to findings from previous studies, we do not find that those least likely to study abroad benefit the most from it. Rather, there is a tendency that groups with the greatest likelihood of studying abroad are those who benefit most.
\end{abstract}

Keywords International student mobility $\cdot$ Short-term mobility $\cdot$ Exchange mobility $\cdot$ Labour market outcomes $\cdot$ Internationalisation

Jannecke Wiers-Jenssen

jann@oslomet.no

Liv Anne Støren

liv.storen@nifu.no

1 Oslo Metropolitan University, Oslo, Norway

2 Nordic Institute for Studies in Innovation, Research and Education (NIFU), Oslo, Norway 


\section{Introduction}

Undertaking higher education abroad — international student mobility (ISM) - may have several purposes as well as consequences. With regard to student mobility in Europe, one aspect is that it is seen as a policy tool for enhancing economic development and integration in Europe. However, ISM is also assumed to have positive outcomes for the individual student, one such effect being improved employability (European Commission 2018). A wish for better employment prospects is also a major motivation to study abroad for the students themselves (European Commission 2014).

Enhanced employment prospects may be considered as based on hopeful assumptions and are not necessarily research-based. Studies addressing the experiences of graduates who have been internationally mobile tend to find that graduates assume that their ISM experience has been helpful regarding getting a job (Teichler and Janson 2007; European Commission 2014) and developing skills that may enhance employability such as self-efficacy and people skills (Jones 2013). However, studies that have investigated whether students with ISM experience are more likely to be successful in the labour market compared with students without ISM experience provide limited support for enhanced employment prospects.

In a review of studies addressing labour market effects of ISM, Waibel et al. (2017) find that studies comparing graduates with and without ISM experience show small or no effects of ISM on labour market outcomes such as duration of period between graduation and work and employment rates, while small but significant effects are found on wages. This is particularly true for studies that take selectivity into account, controlling for background characteristics such as social origin. Such findings challenge the widespread notion that education abroad implies a competitive edge in the labour market. However, research has shown that ISM influence 'horizontal' career prospects, implying that graduates with international experience are more likely to obtain jobs with an international dimension compared with graduates without such experience (Wiers-Jenssen 2008; Teichler 2015) and to find employment abroad (Parey and Waldinger 2010; Oosterbeek and Webbink 2011).

The main purpose of this paper is to examine whether the (possible) benefits of ISM vary between groups, i.e. whether they vary according to social origin, intake score and fields of study. Hence, we investigate what is often labelled as 'heterogeneous effects' (Brand and Xie 2010), meaning that some groups may benefit more than others. The paper considers potential differences between graduates with and without ISM experience, taking into account characteristics of the graduates who were present prior to the sojourn abroad, thus adding knowledge to the issue whether labour market outcomes are related to the sojourn abroad itself, or to characteristics of those who engage in ISM.

The paper investigates whether engaging in short-term ISM (typically 1-2 semesters) enhances the likelihood of a smooth transition from higher education to work for graduates in Norway. Three outcomes referring to the transition phase are examined as follows: the likelihood of being unemployed or severely mismatched, versus being employed in a relevant job position 6 months after graduation. The three outcomes refer to one dependent variable; thus, multinomial logistic regressions are used, which enables us to examine simultaneously a variable with more than two categorical outcomes.

We use a unique set of time series data from the Norwegian Graduate Survey containing information on almost 20,000 graduates with and without ISM experience in the period 20072017. The use of time series data, as well as including immigrant background in the analyses, adds further insight into this field of research. 


\section{Student flows and policy context}

Increasing numbers of students are crossing international borders to undertake higher education. The number of students enrolled in higher education outside their home country has increased from 2 million in 1999 to more than 5 million in 2017 worldwide (OECD 2019). The largest flows of students go from Asian and developing countries to Western countries, but there is also substantial mobility from and between Western countries. Much of the latter ISM is taking place in the form of short-term stays abroad, often labelled 'credit mobility' or 'exchange mobility'. We prefer to use the term 'short-term mobility' as ISM do not necessarily take place within an exchange programme, nor generate credits. The European Union student exchange programme, ERASMUS, later ERASMUS+, has played an important role regarding short-term intra-European mobility. During the three decades this programme has existed, more than 4.4 million students in higher education have participated (European Commission 2017).

Policy rationales for international student mobility are complex and often divided into four broad categories as follows: economic, academic, social/cultural and political (Blumenthal et al. 1996; van der Wende 1997; de Wit 2002; Knight 2004). Several scholars have observed a trend towards more emphasis on economic and academic rationales (e.g. de Wit 2013). Such a development is reflected in policy documents, also in Norway. ISM is encouraged based on an assumption that it will contribute to enhanced quality and a more competitive labour force (Ministry of Education and Research 2009, 2017). Increasing the numbers of students going on short-term mobility abroad is high on the agenda in higher education policy. Making ISM mandatory has even been suggested by the minister for higher education. ISM is facilitated by a generous public student support system; hence, the economic barriers for studying abroad are relatively low in Norway compared with other countries.

Encouraging short-term ISM became an integral part of Norwegian educational policy in the late 1980s, accentuated in the Bologna process, and a higher education reform referred to as the Quality Reform implemented 2003. In addition to the ERASMUS programme, a range of bi- and multilateral agreements between Norwegian and foreign institutions exist. Fifteen per cent of all graduates have engaged in ISM as a part of their Norwegian degree (Ministry of Education and Research 2017); the proportion is higher for master graduates, as is shown later. Every year, around $3 \%$ of the total student body engage in short-term ISM. Students taking a full degree abroad constitute a larger proportion, around 6-7\% at any given time. This outward mobility rate in Norway is higher than observed in most Western countries and has been even higher in previous decades, up to $30 \%$ in the 1950s (Ministry of Education and Research 2009). Hence, ISM is neither a new nor an exceptional phenomenon among Norwegian graduates. This implies that graduates with ISM experience may stand out less than in countries where ISM experience is less common.

\section{Theoretical considerations and previous research}

ISM can have positive effects on labour market outcomes resulting from the human and social capital acquired. Students can gain academic skills abroad, but they may also develop language skills, cultural skills, networks and so forth. Such skills can be seen as an added value.

In line with signalling theory, ISM experience may also be an advantage due to its function as a screening device (Arrow 1973; Spence 1973). Potential employers lack information about 
the quality of job seekers. According to signalling theory, acquired education serves as a signal of quality and may reduce employers' uncertainty, i.e. reduce 'information asymmetries' (Connelly et al. 2011, p. 42). ISM experience may further increase the information about the job seeker and signal certain features perceived as valuable by employers.

Students engaging in ISM may also have a competitive advantage if they constitute a selected group in the first place. If those who have studied abroad differ from graduates with an all-domestic education regarding features that normally reduce or increase the employment prospects, differences in labour market outcomes may reflect this more so than the ISM experience itself. Hence, it is important to conduct multivariate analyses controlling for subject field as well as sociodemographic and human capital variables.

Several studies have shown that students engaging in ISM have a higher social origin than those who do not (Blanck and Börjesson 2008; Otero 2008; Brooks and Waters 2011; Gerhards and Hans 2013; European Commission 2016). It is also noted that short-term ISM students have higher intake scores and that they are less likely to have an immigrant background compared with non-mobile students (King, Findlay and Ahrens 2010). Based on this, we assume that graduates with ISM experience constitute a positively selected group regarding background characteristics.

Analyses of transitions from higher education to work have shown that the labour market entry is smoother for some groups than others. For instance, subject field is decisive. A survey including many European countries, the REFLEX study, shows that graduates in vocationally oriented programmes like computing, engineering, health welfare, and education experience less mismatch in the labour market than graduates in generic programmes such as the humanities and social sciences (Støren and Arnesen; 2011, Verhaest and van der Velden 2012). The REFLEX study also shows that relevant working experience prior to graduation as well as good grades reduce the probability of mismatch (Støren and Arnesen 2011). These patterns are also seen in more recent studies from Norway (Thune and Støren, 2015; Støren and Arnesen, 2016). Immigrant background, also among persons with higher education, is shown to have negative effect on employment prospects in Norway (Støren and WiersJenssen, 2010) and other countries (Frickey, Murdoch, and Primon 2006; Heath, Rothon, and Kilpi 2008; Yssaad 2012; OECD/European Union 2015). However, less is known about whether ISM alters the positive (e.g. vocational field of study, previous working experience) and negative factors (e.g. immigrant background), described above.

Kratz and Netz (2018) analysed financial returns of ISM based on data from Germany. They find that graduates with ISM experience have a steeper wage development in their early career. Their multivariate analyses show that this is partly due to favourable self-selection and partly due to more frequent changes of employer and the better access of ISM-experienced graduates to large and multinational companies. Waibel, Petzold and Rüger (2018, p. 57) found 'slight occupational status differences between graduates who studied abroad and those who did not' even after controlling for selection of high-achievement groups into study abroad.

In a review of surveys conducted among graduates who have participated in the ERASMUS programme, Teichler (2015) finds that graduates with ISM experience received a small wage premium compared with graduates with an all-domestic education. Graduates with ISM experience reach slightly higher positions in the initial phases of their career. It should be noted that the ERASMUS surveys are mainly descriptive and do not control for background characteristics. However, investigating if outcomes vary by home country, Teichler finds that some groups may benefit more than others in the labour market. ERASMUS students from Central and Eastern European countries have a higher professional award. A study from 
Poland supports the latter (Liwiński 2016). A study of the impacts of ERASMUS Europe (European Commission 2016) shows that former ERASMUS students from Southern Europe, and to some extent from Eastern Europe, have a lower risk of unemployment compared with students without ISM experience while this difference is far less pronounced among students from Northern Europe. Similar patterns are seen in recent research based on data from the REFLEX study (Jacob, Kühhirt and Rodrigues 2019). This indicates that ISM may be an advantage in some countries, particularly those with weak traditions for mobility and/or where the unemployment among graduates is generally high.

Research investigating the demand side of education abroad shows that ISM experience plays a more limited role than is often assumed. Studies of recruitment strategies of European employers show that experience from abroad is not regarded as a particularly important recruitment criterion (Humburg and van der Velden 2015; Van Mol 2017). A study of German employers' attitudes to education abroad finds that experience from abroad does not serve as a general job performance signal but that it is accentuated when companies search for employees to international jobs (Petzold 2017). A recent study among Norwegian employers shows that experience from abroad is not considered an important recruitment criterion; only $3 \%$ of those who engage master graduates consider experience from abroad as very important, and $23 \%$ as quite important (Støren et al. 2019).

The above review refers mainly to studies looking at the overall body of graduates, not subgroups. Importantly, however, the benefit of studying abroad may vary between groups, i.e. the effects of ISM can be heterogeneous. One possible reason for this is that those who belong to the group of students who is most likely to study abroad will benefit most, because this group already possesses characteristics that make the transition to the labour market easier; Brand and Xie (2010) refer to such mechanisms as based on principles of comparative advantage, where positive selection is at work (Brand and Xie 2010, p. 273). They formulate a positive selection hypothesis as follows: 'individuals who are most likely to select into college also benefit most from college'. Another possibility is that those who are least likely to study abroad benefit more. Brand and Xie (op.cit,) also suggest a 'negative selection hypothesis', i.e. that individuals who are least likely to go to college - in our case least likely to study abroad - can be those who benefit most from it. To some extent this can be interpreted as being in line with the findings of Waibel et al. (2018), who found that status returns to ISM (referring to occupational status) are less expressed for those who have a higher propensity to study abroad than the returns to studying abroad achieved by low-propensity graduates. The groups with low propensity to study abroad included individuals with the least economic, social and cultural resources (Waibel et al. 2018).

Waibel et al. (op. cit.) argue that for graduates with a lower propensity to study abroad, this may 'play a stronger market-signalling role in setting themselves apart from their peers'. They also refer to Di Pietro (2015), who argues that ISM may provide those who are less likely to study abroad with language skills and intercultural skills, etc., which students with high propensity to study abroad already possess. Di Pietro finds that ISM experience increases employment prospects among Italian graduates and that this particularly applies to students from disadvantaged backgrounds. Partly in line with this, Liwiński (2016) finds that the wage premium of studying abroad is particularly high among Polish graduates with lower average grades. Hence, it seems that higher education abroad may compensate for poor school performance. 
Waibel et al. (2018) find heterogeneous effects concerning fields of study. For graduates trained for 'occupationally specific fields', they found no evidence that ISM increased occupational status. However, for graduates in unspecific fields, they find net benefits of ISM. To some extent, subject fields are also related to different segments of the labour market. Some parts of the labour market are more internationally oriented than others, and international experience may be in higher demand. Liwiński's (2016) research from Poland illustrates this when he finds that a wage premium for education abroad is only found in the private sector. Research from Norway has also shown wage premiums for working in the private sector and international firms (Wiers-Jenssen and Try, 2005).

\section{Hypotheses}

Graduates with ISM experience may have slightly better labour market prospects than graduates without such experience due to advantages connected to positive self-selection, additional skills (human capital), signalling effects or a combination of these. However, previous research tends to find that the positive effects of ISM diminish when controlling for background characteristics, and this is also shown for Norway (Wiers-Jenssen and Try, 2005). In line with this, our first hypothesis reads:

H1: There are no differences between graduates with and without ISM experience regarding the risk of unemployment and holding irrelevant work six months after graduation, when controlling for relevant background characteristics.

Although we expect no effect of ISM in general, i.e. for the average of overall body of graduates (H1), it is reasonable to expect — based on previous research mentioned above - that positive effects of ISM on labour market adaptation can exist for some subgroups of graduates. It may, for example, be more prominent in some fields than in others. Waibel et al. (2018) found differences between vocationally specific and generic fields. We expect that also other patterns of differences regarding subject fields may exist dependent upon the extent to which the subject field is a recruitment base for the private rather than the public sector (cf. Liwiński 2016, who finds a wage premium of ISM only in the private sector). The signalling effect of ISM can be greater in the more competitive private sector than in the public sector. ${ }^{2}$ We expect that in the more competitive private sector, experience from study abroad will have larger impact on job prospects than in the public sector. In Norway; technology graduates and business and administration graduates are more likely than other groups to be employed in the private sector.

H2: A positive effect of ISM experience on the labour market adaptation exists for graduates in fields of study that mainly recruit to the private sector, but not for other graduates.

In $\mathrm{H} 2$ and in the following hypotheses, a 'positive effect on labour market adaptation' implies 'reducing the risk of unemployment and holding irrelevant work six months after graduation'.

\footnotetext{
${ }^{1}$ The authors categorized law, medicine, teaching, engineering, architecture, computer science, and related natural sciences, and public administration as occupationally specific fields of study. Occupationally unspecific fields are other educational sciences, social sciences, psychology, life science, math and statistics as well as technical and commercial subjects were identified to be (Waibel et al. 2018, p. 51).

${ }^{2}$ This is in line with findings that the signalling effects of education are higher in the private sector than in the public sector and that wage determination is different in the public and private sectors (Harmon, Walker and Westergaard-Nielsen 2001).
} 
The findings in studies mentioned above (Di Pietro 2015; Waibel et al. 2018; Liwiński 2016), which give support the negative selection hypothesis, give reason to expect that those with the lowest likelihood of studying abroad will benefit most from ISM and that the signalling effects of ISM are stronger for these graduates. As mentioned above, it is a common finding that students with the least likelihood of studying abroad are a negatively selected group regarding social background and intake grades. Based on this, the next three hypotheses are formulated.

H3: A positive effect of ISM experience on the labour market adaptation exists for graduates with low intake grades, but not for graduates with higher intake grades.

H4: A positive effect of ISM experience on the labour market adaptation exists for graduates with low parental education level, but not for graduates with higher parental education level.

H5: A positive effect of ISM experience on the labour market adaptation exists for graduates with non-Western immigrant background, but not for non-immigrant graduates.

Regarding the possible heterogeneous effects of social origin, the effects can also be contrary to what is expected in $\mathbf{H 4}$, which is based on the theory that those with the lowest likelihood of studying abroad will benefit most from ISM. It is well known that students with an academic background are more likely to engage in ISM than those with low parental education level. An argument for that the effects can be contrary to what is expected in $\mathbf{H 4}$ is that those with highly educated parents will benefit more than others from ISM experience because they effectively can use it as an additional value to their high amounts of social capital and also be more strategic in their choice of host country and higher education institution.

Also regarding grades, the effects may be contrary to what is expected in $\mathbf{H 3}$. A premise for $\mathrm{H} 3$ is that studying abroad can compensate to some extent for poor academic performance, but a Matthew effect of accumulated advantage (Merton 1968) is just as likely, i.e. that those who have good grades will benefit most from ISM.

Finally, to our knowledge, the impact of being a non-Western immigrant on the (possible) effect of studying abroad (H5) has not been studied previously. Having non-Western immigrant background is generally a disadvantage regarding labour market outcomes, and we consequently investigate whether study abroad plays a market-signalling role that improves labour market prospects.

\section{Data}

We employ data from the Norwegian Graduate Survey, collected approximately 6 months after graduation. This survey is conducted biennially and distributed to persons graduating in the spring term with a master's degree. With a few exceptions, all graduates from Norwegian higher education institutions are included. ${ }^{3}$ The overall response level is high, around $50 \%$, with some variation between years.

\footnotetext{
${ }^{3}$ In addition to a master's degree, three groups of higher degree graduates in psychology, theology and veterinary medicine are included. Human medicine is not included due to an internship period requirement to get authorization after graduation. One private business school is not included because it does not want to participate in the national graduate survey. For some years (the surveys in 2007 and 2011), a stratified sampling has been used. For these samples, the data is weighted according to the sampling procedure. The number of observations in the tables is unweighted.
} 
Six cohorts are included (alternate years 2007-2017), and the total number of graduates in these surveys is 19,179 . The labour market situation in Norway for fresh graduates changed substantially during this period, and controls for year of graduation are included. The graduates obtained their master's degree from a Norwegian institution. About one in four has engaged in ISM as a part of this degree.

The questionnaire included a range of questions regarding transition from higher education to work and background variables such as gender, parents' level of education and immigrant background. Information about the business sector is available, but as the regressions include unemployed persons (see the Methods section below), for whom information about the organization is not relevant, such variables are not included in the regressions.

\section{Methods}

The results are displayed in descriptive bivariate tabulations as well as in multivariate regressions. The multivariate regressions have three outcomes of which two refer to labour market marginalization. One form of marginalization is 'unemployment'; the other is 'involuntary irrelevant work'. The reason for analysing two outcomes referring to labour market marginalization is outlined below. The third outcome in the regression is 'holding relevant work'.

The graduates were asked about their employment situation during a specific week in November, approximately 6 months after graduation. At this stage, it is quite common not to be fully integrated to the labour market, and, for example, to have a job for which one is somewhat overeducated. Hence, to give a realistic picture of labour market problems, we focus on more extreme forms of maladjustment, that is, involuntarily having irrelevant work and unemployment. Graduates who are somewhat overeducated for their job 6 months after graduation are considered as having relevant work.

Involuntary irrelevant work is a measure of (extreme) vertical and horizontal skills mismatch. The definition includes graduates who report (i) that higher education is irrelevant for the job, (ii) that the content of the education they completed in the spring semester did not correspond at all with the work they do in their current job and (iii) that it had not been possible to find work that corresponded to their educational qualifications.

Those who are unemployed do not have paid work. Further, they have been actively seeking work and report that if they had received an offer of employment, they would have been able to take up this post.

The main point here is that unemployment and involuntary irrelevant work are both expressions of severe maladjustment in the labour market, and if looking solely at unemployment, we miss crucial information. Further, these two forms of maladjustment can apply differently to different groups of graduates.

We have no information on why some persons prefer irrelevant work rather than being unemployed, but two probable reasons can be outlined. One refers simply to the cost of living; they need to have an income, and they are possibly not entitled to unemployment benefits, or the unemployment benefits are less beneficial than the income from irrelevant work. Another reason can apply to some groups of graduates more than others. Based on experiences from their peers or previous graduate surveys, ${ }^{4}$ one group might expect that graduates in their subject field (for example, the humanities) really need some time to obtain a relevant job, and

\footnotetext{
${ }^{4}$ Norwegian graduate surveys show that graduates in the humanities are overrepresented among those who are overeducated 6 months after graduation (Støren and Wiers-Jenssen 2016).
} 
in the meantime, they accept an irrelevant job. They may also think that it is more beneficial to apply for a job from a position where they are not unemployed. Likewise, we have no precise information on why some persons are unemployed rather than holding irrelevant work. Some have other means to cover their cost of living while seeking appropriate employment, some have not received any job offer and others expect that they soon will receive an appropriate job offer.

Based on the above considerations, the dependent variable in the multivariate regression has three outcomes as follows: 'unemployment', 'involuntary irrelevant work' and 'relevant work'.

Multinomial logistic regressions make it possible to use a dependent variable with more than two categorical outcomes. They allow us to examine the probabilities of the different outcomes simultaneously and, for example, to examine the effects of intake grades on both the outcomes 'unemployment' and 'involuntary irrelevant work', versus 'relevant work'. The third outcome is used as the reference category.

Persons in relevant work who are underemployed (work part-time because it was not possible to get a full-time job), and persons holding irrelevant work of own choice are excluded from the regression analyses where only the categories 'unemployment', 'involuntary irrelevant work' and 'relevant work' are included. The reason why the underemployed and those having voluntary irrelevant work are not included in the regressions is mainly practical. The use of five outcomes on the dependent variables results in rather complex tables. Further, these groups are quite small (see Table 2). The purpose of the regression is to focus on the risk of being severely maladjusted compared with having relevant work and not, for instance, compared with being underemployed.

Regressions are run for the total group of graduates, including interaction terms. The interaction terms allow us to examine possible heterogeneous effects, i.e. to examine whether the effects of ISM vary between the groups according to fields of study, intake grades, parental education and immigrant background (cf. H2-H5). Based on Mood (2010), this procedure is chosen instead of conducting separate (comparative) analyses of different groups. Further, the coefficients in the regressions are reported as average marginal effects (AME), following recommendations of Mood (2010), Williams (2012) and Ai and Norton (2003). Otherwise, interaction effects (in terms of a logit) can give incorrect estimates in nonlinear models. Further, this method provides intuitively readable results, because the coefficients refer to the average change in probability when a variable, for instance having ISM experience, increases by one unit.

The ISM and other independent variables are described in Appendix 1. In addition to ISM, year of graduation, parental education level, field of study, intake grades, immigrant background and work experience before graduation are controlled for. Mean sample values of the independent variables are displayed in Table 8. The variation in ISM experience between fields of study is further described below (Table 1). Except for work experience before graduation, these are all variables which refer to the situation prior to higher education. The distribution of the background characteristics shows that graduates who have studied abroad to some extent represent a positively selected group (see Table 8). They are overrepresented among graduates with both parents holding higher education and among graduates with the highest intake grades and are underrepresented among immigrant graduates of non-Western origin. Although unobserved heterogeneity still exists, we are confident that the control variables used (including fields of study, cohort, intake grades, etc.) are central factors regarding the variation in graduates' employment situation. 
Table 1 Graduates in the spring terms 2007, 2009, 2011, 2013, 2015 and 2017 by field of study, ISM experience (per cent of all graduates)

$$
\text { Per cent with ISM experience } \quad N \text {, unweighted, valid }
$$
response $(=100 \%)$

Humanities and arts

Pedagogy and teacher training

Social science

Law

Business and administration

Natural science

Technology (graduate engineering)

Health and welfare

Sport and physical education

Primary industries

Transport, communications, safety, services

Total

$\begin{array}{rr}24.5 & 2687 \\ 9.4 & 2123 \\ 33.4 & 2988 \\ 24.3 & 1230 \\ 36.4 & 2530 \\ 21.5 & 2681 \\ 31 & 1813 \\ 10.4 & 2340 \\ 13.7 & 359 \\ 18.6 & 247 \\ 12.2 & 181 \\ 24.1 & 19,179\end{array}$

The proportion of graduates with ISM experience varies widely between subject fields (see Table 1). Business and administration, social science and technology have the highest proportions (31-36\%). In total, one fourth of the graduates have had a study sojourn abroad. The vast majority of graduates with ISM experience, $91 \%$, have had a sojourn abroad of one to two semesters (3-12 months), and the most typical duration of the study sojourn was 5-6 months.

\section{The labour market situation—descriptives}

The labour market situation in the period 2007-2017 varied between the educational groups as well as between the cohorts. In Table 2, different forms of adaptation to the labour market are displayed for each cohort and according to ISM experience.

Table 2 The labour market situation 2007-2017 6 months after graduation

\begin{tabular}{lllllll}
\hline & $\begin{array}{l}\text { Employed in } \\
\text { relevant work }\end{array}$ & Unemployed & Under-employed & $\begin{array}{l}\text { Involuntary } \\
\text { irrelevant work }\end{array}$ & $\begin{array}{l}\text { Irrelevant work } \\
\text { of own choice }\end{array}$ & $\begin{array}{l}N=100 \%, \\
\text { (unweighted) } \\
\text { persons in the } \\
\text { labour force }\end{array}$ \\
\hline ISM & & & & & & \\
2007 & 86.7 & & & & & 526 \\
2009 & 81.1 & 4.3 & 3.7 & 2.3 & 3.1 & 678 \\
2011 & 83.1 & 7.1 & 4.9 & 4.4 & 2.5 & 542 \\
2013 & 83.5 & 5.4 & 4.6 & 5.3 & 1.6 & 723 \\
2015 & 77.9 & 6.2 & 4.4 & 5.0 & 0.8 & 963 \\
2017 & 77.3 & 8.7 & 5.1 & 6.9 & 1.5 & 893 \\
Total & 81.4 & 7.3 & 6.3 & 7.1 & 2.1 & 1831 \\
No ISM & 6.5 & 4.9 & 5.2 & 1.9 & 2054 \\
2007 & 85.3 & & & & 1568 \\
2009 & 83.4 & 3.7 & 4.0 & 3.8 & 3.2 & 2332 \\
2011 & 83.2 & 5.8 & 4.4 & 4.5 & 1.9 & 2733 \\
2013 & 80.4 & 6.0 & 4.3 & 4.9 & 1.7 & 3364 \\
2015 & 76.6 & 6.9 & 6.3 & 4.6 & 1.8 & 13,882 \\
2017 & 78.1 & 7.8 & 7.9 & 5.5 & 1.1 & \\
Total & 80.9 & 6.6 & 6.7 & 6.2 & 1.8 & \\
\hline
\end{tabular}

Graduates with and without ISM experience (per cent of graduates in the labour force) 
To give a full picture of the situation, Table 2 includes information on persons who are underemployed (working part-time because it was not possible to get a full-time job) and persons holding irrelevant work of own choice. As mentioned above, these groups are excluded in the regression analyses below, where only the categories 'unemployment', 'involuntary irrelevant work' and 'relevant work' are included.

The labour market situation is very similar for graduates with and without ISM experience, irrespective of cohort (Table 2). The labour market situation has changed over time, but the difference in unemployment rates between ISM graduates and other graduates do not differ significantly between cohorts. The labour market situation was particularly favourable in 2007 but has become more difficult in recent years (see also Table 9). The increase in the unemployment level in 2015 mainly concerned graduates in science and engineering/ technology.

Table 3 illustrates the differences and similarities between graduates with and without ISM experience in the different subject fields. Three smaller subject fields are excluded, i.e. sports and physical education; primary industries; and transport, communications, safety and services. Graduates in these fields are also excluded in the regression analyses below.

The labour market situation varies between fields of study (Table 3), as does the prevalence of ISM experience (Table 1). This emphasizes that it is important to control for field of study. Table 3 reveals one major difference between graduates with and without ISM experience concerning the unemployment rate. This refers to technology graduates in 2017; those with ISM experience had lower unemployment than those who had not. We examined whether this large difference $(5.5 \%$ versus $19.7 \%$ ) can be attributed to a different distribution of narrow fields of education among technology graduates with and without ISM experience and found that this is not the case. Examples (referring to fields and cohorts) of ISM graduates having a significantly lower unemployment rate than non-mobile graduates are highlighted in Table 3. We do not find clear signs of systematic differences between graduates with and without ISM

Table 3 Unemployed graduates 6 months after graduation by cohort, field of study and ISM experience (per cent of graduates in the labour force)

\begin{tabular}{llllrllll}
\hline & $\begin{array}{l}\text { Humanities } \\
\text { and arts }\end{array}$ & $\begin{array}{l}\text { Pedagogy and } \\
\text { teacher } \\
\text { training }\end{array}$ & $\begin{array}{l}\text { Social } \\
\text { science }\end{array}$ & Law & $\begin{array}{l}\text { Business and } \\
\text { administration }\end{array}$ & $\begin{array}{l}\text { Natural } \\
\text { science }\end{array}$ & $\begin{array}{l}\text { Technology } \\
\text { (graduate } \\
\text { engineering) }\end{array}$ & $\begin{array}{l}\text { Health } \\
\text { and } \\
\text { welfare }\end{array}$ \\
\hline ISM & & & & & & & & \\
2007 & 5.2 & $:$ & 4.6 & 4.2 & 8.8 & 2.0 & 2.8 & 0 \\
2009 & 6.6 & 7.1 & 7.9 & 5.3 & 6.6 & 8.0 & 8.5 & 0 \\
2011 & 7.1 & 0 & 8.0 & 6.9 & 2.3 & 7.8 & 2.9 & 7.0 \\
2013 & 7.7 & 9.7 & 7.8 & 3.6 & 7.6 & 5.6 & 3.8 & 2.4 \\
2015 & 10.5 & 0 & 11.0 & 7.3 & 5.3 & 12.1 & 14.3 & 0 \\
2017 & 10.2 & 2.3 & 8.0 & 5.6 & 5.2 & 12.0 & 5.5 & 5.2 \\
Total & 7.6 & 2.8 & 7.7 & 5.5 & 5.7 & 8.3 & 6.8 & 2.9 \\
No ISM & & & & & & & & 1.9 \\
2007 & 5.0 & 2.7 & 3.3 & 1.0 & 5.2 & 7.2 & 1.1 & 1.1 \\
2009 & 6.6 & 0.8 & 5.9 & 6.9 & 7.9 & 9.6 & 6.9 & 3.3 \\
2011 & 7.3 & 2.4 & 6.0 & 8.1 & 4.7 & 10.0 & 4.8 & 3.8 \\
2013 & 8.8 & 2.5 & 7.3 & 6.9 & 7.7 & 11.1 & 6.7 & 4.6 \\
2015 & 9.7 & 3.4 & 11.1 & 9.3 & 7.0 & 14.5 & 15.7 & 3.2 \\
2017 & 6.0 & 3.2 & 10.4 & 10.2 & 5.7 & 14.4 & 19.7 & 3.2 \\
Total & 7.0 & 2.7 & 7.4 & 7.1 & 6.3 & 11.3 & 8.8 & 3.3 \\
\hline
\end{tabular}

Too low number base 
experience because the direction of the observed differences varies between cohorts and fields of study and are frequently small and non-significant.

\section{Multivariate regressions}

The results of multinomial regressions are shown in Tables 4, 5, 6, and 7. The number of observations $(15,213)$ included in the regression analyses are reduced compared with Table 1 due to the exclusion of certain groups described above, as well as persons outside the labour force and observations with missing values on independent variables. Four regression models were run in order to test $\mathrm{H} 2-\mathrm{H} 5$. Interaction terms for fields of study and ISM experience are included in Table 4; interaction terms for intake grades and ISM experience are included in Table 5; interaction terms for parental education level and ISM experience are included in Table 6 and one interaction term for being a non-Western immigrant and ISM experience is included in Table 7. Otherwise, the models are similar in the four tables.

The general effects of ISM on the likelihood of being unemployed or of having irrelevant work are small and insignificant, when controlling for graduates' background characteristics. This supports H1. ISM may still have different effects for the different groups, i.e. possible heterogeneous effects. This is analysed by including interaction terms, as shown below (under the heading 'Heterogeneous effects').

However, several other variables than ISM have a great impact on the transition from education to work. The average distribution on the dependent variable among the cases that are included in the regression is that $7 \%$ are unemployed, $5.4 \%$ are holding irrelevant work, whereas 87.5 are holding relevant work. This implies that when the probability of being unemployed increases by 5.7 percentage points for non-Western immigrants compared with non-immigrants (the reference group) (cf. Table 4); this is a considerable increase. For those who did not live in Norway at the age of 17 , the risk of maladjustment is further increased. Business cycles (year of graduation) are also important. For example, having graduated in 2015 decreases the probability of having relevant work with 9.4 percentage points compared with 2007, which is the reference year. Correspondingly, the probability of being unemployed or having irrelevant work is increased by 5.9 and 3.44 percentage points respectively, cf. Table 4.

Other variables with a large impact are fields of study, intake score and work experience before graduation. If one has experience with relevant paid work during study, the probability of having relevant work 6 months after graduation is increased by 10 percentage points, and the corresponding probability of being unemployed or having irrelevant work is decreased by 7.8 and 2.2 percentage points, respectively (cf. Table 4). Parental education level has very little influence. When both parents have higher education, the probability of having irrelevant work is decreased by one percentage point compared with medium educated parents; otherwise, no significant effects concerning parental education level are found.

\section{Heterogeneous effects}

\section{Fields of study}

One reason for expecting variation according to fields of study is the variation between the fields in the proportion seeking employment in the private sector (see Table 10). According to our considerations in the introductory part (see H2), ISM experience should have a larger 
Table 4 The probability of being unemployed, having involuntary irrelevant work or having relevant work

\begin{tabular}{|c|c|c|c|}
\hline ISM experience (study abroad) & $\begin{array}{l}\text { Unemployed } \\
-0.0144\end{array}$ & $\begin{array}{l}\text { Irrelevant work } \\
0.0093\end{array}$ & $\begin{array}{l}\text { Relevant work } \\
0.0051\end{array}$ \\
\hline \multirow[t]{2}{*}{ Female } & $(0.0113)$ & $(0.0097)$ & $(0.0142)$ \\
\hline & $-0.0140 * * *$ & 0.0038 & $0.0102 *$ \\
\hline \multirow[t]{3}{*}{ Age } & $(0.0043)$ & $(0.0038)$ & $(0.0055)$ \\
\hline & 0.0001 & $-0.0016^{* * *}$ & $0.0016^{* * *}$ \\
\hline & $(0.0003)$ & $(0.0003)$ & $(0.0004)$ \\
\hline \multirow[t]{2}{*}{ Cohort 2009} & $0.0356^{* * * *}$ & 0.0108 & $-0.0465 * * *$ \\
\hline & $(0.0093)$ & $(0.0076)$ & $(0.0111)$ \\
\hline \multirow[t]{2}{*}{2011} & $0.0256^{* *}$ & $0.0178 * *$ & $-0.0434 * * *$ \\
\hline & $(0.0100)$ & $(0.0080)$ & $(0.0119)$ \\
\hline \multirow[t]{2}{*}{2013} & $0.0403 * * *$ & $0.0201 * * *$ & $-0.0604 * * *$ \\
\hline & $(0.0091)$ & $(0.0074)$ & $(0.0109)$ \\
\hline \multirow[t]{2}{*}{2015} & $0.0594 * * *$ & $0.0344 * * *$ & $-0.0938 * * *$ \\
\hline & $(0.0086)$ & $(0.0069)$ & $(0.0102)$ \\
\hline \multirow[t]{2}{*}{2017} & $0.0536 * * *$ & $0.0389 * * *$ & $-0.0925 * * *$ \\
\hline & $(0.0086)$ & $(0.0068)$ & $(0.0101)$ \\
\hline \multirow[t]{2}{*}{ Relevant work before graduation } & $-0.0779 * * *$ & $-0.0220 * * *$ & $0.0999 * * *$ \\
\hline & $(0.0056)$ & $(0.0060)$ & $(0.0076)$ \\
\hline \multirow{2}{*}{ Non-relevant (only) work before graduation } & $-0.0307 * * *$ & $0.0577 * * *$ & $-0.0270 * * *$ \\
\hline & $(0.0053)$ & $(0.0055)$ & $(0.0074)$ \\
\hline \multirow[t]{2}{*}{ Pedagogy } & $-0.0646^{* * *}$ & $-0.0531 * * *$ & $0.1177 * * *$ \\
\hline & $(0.0112)$ & $(0.0114)$ & $(0.0146)$ \\
\hline \multirow[t]{2}{*}{ Humanities and arts } & -0.0051 & $0.0347 * * *$ & $-0.0297 * * *$ \\
\hline & $(0.0082)$ & $(0.0067)$ & $(0.0102)$ \\
\hline \multirow[t]{2}{*}{ Business \& administration } & $-0.0264 * * *$ & $-0.0142 *$ & $0.0407 * * *$ \\
\hline & $(0.0086)$ & $(0.0081)$ & $(0.0111)$ \\
\hline \multirow[t]{2}{*}{ Law } & -0.0075 & 0.0000 & 0.0074 \\
\hline & $(0.0099)$ & $(0.0086)$ & $(0.0125)$ \\
\hline \multirow[t]{2}{*}{ Social science } & -0.0070 & $0.0207 * * *$ & -0.0137 \\
\hline & $(0.0077)$ & $(0.0066)$ & $(0.0097)$ \\
\hline \multirow[t]{2}{*}{ Technology/engineering } & $-0.0217 * *$ & $-0.0288 * * *$ & $0.0505 * * *$ \\
\hline & $(0.0085)$ & $(0.0096)$ & $(0.0120)$ \\
\hline \multirow[t]{2}{*}{ Health and welfare } & $-0.0528 * * *$ & $-0.0169^{*}$ & $0.0696^{* * *}$ \\
\hline & $(0.0100)$ & $(0.0088)$ & $(0.0124)$ \\
\hline \multirow[t]{2}{*}{ Medium intake grades } & $-0.0156^{* * *}$ & -0.0060 & $0.0215^{* * *}$ \\
\hline & $(0.0052)$ & $(0.0044)$ & $(0.0065)$ \\
\hline \multirow[t]{2}{*}{ High intake grades } & $-0.0284 * * *$ & $-0.0270 * * *$ & $0.0554 * * *$ \\
\hline & $(0.0054)$ & $(0.0049)$ & $(0.0069)$ \\
\hline \multirow[t]{2}{*}{ Both parents higher education } & -0.0001 & $-0.0130 * *$ & 0.0132 \\
\hline & $(0.0064)$ & $(0.0055)$ & $(0.0080)$ \\
\hline One parent higher education & 0.0019 & -0.0081 & 0.0062 \\
\hline & $(0.0069)$ & $(0.0058)$ & $(0.0085)$ \\
\hline Low educated parents & -0.0080 & 0.0072 & 0.0008 \\
\hline & $(0.0081)$ & $(0.0065)$ & $(0.0099)$ \\
\hline Lived outside Norway at age 17 & $0.0406^{* * * *}$ & $0.0254 * * *$ & $-0.0660 * * *$ \\
\hline & $(0.0095)$ & $(0.0090)$ & $(0.0127)$ \\
\hline Non-Western immigrant & $0.0571 * * *$ & $0.0208 * *$ & $-0.0779 * * *$ \\
\hline & $(0.0095)$ & $(0.0091)$ & $(0.0129)$ \\
\hline Western immigrant & 0.0160 & -0.0117 & -0.0043 \\
\hline & $(0.0124)$ & $(0.0122)$ & $(0.0168)$ \\
\hline Second-generation immigrant & 0.0231 & 0.0177 & $-0.0408 * *$ \\
\hline & $(0.0157)$ & $(0.0124)$ & $(0.0194)$ \\
\hline ISM* Pedagogy & 0.0316 & -0.0268 & -0.0048 \\
\hline & $(0.0308)$ & $(0.0375)$ & $(0.0440)$ \\
\hline ISM* Humanities and arts & $0.0274 *$ & -0.0100 & -0.0173 \\
\hline & $(0.0166)$ & $(0.0132)$ & $(0.0203)$ \\
\hline
\end{tabular}


Table 4 (continued)

\begin{tabular}{llll}
\hline ISM experience (study abroad) & $\begin{array}{l}\text { Unemployed } \\
-0.0144\end{array}$ & $\begin{array}{l}\text { Irrelevant work } \\
0.0093\end{array}$ & $\begin{array}{l}\text { Relevant work } \\
0.0051\end{array}$ \\
\hline ISM* Business \& administration & -0.0018 & $-0.0408^{* * *}$ & $\begin{array}{l}0.0427^{* *} \\
(0.0213)\end{array}$ \\
ISM* Law & $(0.0164)$ & $(0.0158)$ & 0.0373 \\
& -0.0086 & -0.0286 & $(0.0275)$ \\
ISM* Social science & $(0.0222)$ & $(0.0194)$ & -0.0110 \\
& 0.0200 & -0.0090 & $(0.0186)$ \\
ISM* Technology/Engineering & $(0.0151)$ & $(0.0123)$ & $(0.0236)$ \\
& 0.0008 & -0.0193 & 0.0365 \\
ISM* Health and welfare & $(0.0171)$ & $(0.0187)$ & $(0.0365)$ \\
& -0.0258 & -0.0107 & 15,123 \\
N & $(0.0324)$ & $(0.0227)$ & 15,123 \\
Cragg \& Uhler's R2 (Pseudo R2) & 15,123 & & \\
\hline
\end{tabular}

a Significant at level $p<0.1$. **Significant at level $p<0.05$. ***Significant at level $p<0.01$

Results of multinomial logistic regressions (average marginal effects), including interaction effects of fields of study * ISM experience. Standard errors in parentheses

Reference category in Tables 4, 5, 6, and 7: 2007 cohort, no ISM experience, male, no work experience before graduation, graduated in natural science, low intake grades, medium educated parents (below tertiary), nonimmigrant, lived in Norway age 17

impact on labour market outcomes in the more competitive private sector than in the public sector.

For technology graduates, we found that in the most recent cohort, the unemployment rate was lower among graduates with ISM experience compared with graduates with an alldomestic education (Table 3). However, the interaction effect of being a technology graduate and having ISM experience is insignificant (Table 4). This is the average marginal effect, when all other control variables are fixed. However, for ISM graduates in business and administration, the risk of having involuntary irrelevant work is significantly reduced (4.1 percentage points, see Table 4), and correspondingly, the probability of having relevant work is increased. Otherwise, none of the interaction terms between fields of study and ISM experience are significant. Business and administration graduates as well as technology graduates are both more likely than other groups to be employed in the private sector (see Table 10). Thus, the findings give only partial support to our second hypothesis (H2) (i.e. only applying to the business and administration graduates).

\section{Intake grades, parental education level and immigrant backgrounds}

The interaction effect between 'high intake grades and ISM' is significant, cf. Table 5 (see explanation of the grades variable in Appendix 1). Among graduates with high intake grades, study abroad reduces the risk of unemployment ( 3 percentage points). The results are contrary to the expectations in $\mathbf{H 3}$, which stated that a positive effect of ISM experience on the labour market adaptation exists for graduates with low intake grades, but not for graduates with higher intake grades.

Concerning the possible heterogeneous effects of low and high parental education level, cf. Table 6 (see definition of parental education level in Appendix 1), no effects of studying abroad are found. The findings do not give support to $\mathbf{H} \mathbf{4}$ which stated that a positive effect of 
Table 5 The probability of being unemployed, having involuntary irrelevant work or having relevant work

\begin{tabular}{|c|c|c|c|}
\hline ISM experience (study abroad) & $\begin{array}{l}\text { Unemployed } \\
0.0072\end{array}$ & $\begin{array}{l}\text { Irrelevant work } \\
-0.0112\end{array}$ & $\begin{array}{l}\text { Relevant work } \\
0.0039\end{array}$ \\
\hline \multirow[t]{2}{*}{ Pedagogy } & $(0.0090)$ & $(0.0081)$ & $(0.0116)$ \\
\hline & $-0.0602^{* * * *}$ & $-0.0578^{* * * *}$ & $0.1180^{* * * *}$ \\
\hline \multirow[t]{3}{*}{ Humanities and arts } & $(0.0105)$ & $(0.0108)$ & $(0.0137)$ \\
\hline & 0.0012 & $0.0325^{* * *}$ & $-0.0337^{* * * *}$ \\
\hline & $(0.0072)$ & $(0.0059)$ & $(0.0089)$ \\
\hline \multirow[t]{2}{*}{ Business \& administration } & $-0.0279^{* * *}$ & $-0.0258^{* * *}$ & $0.0537^{* * * *}$ \\
\hline & $(0.0073)$ & $(0.0070)$ & $(0.0094)$ \\
\hline \multirow[t]{2}{*}{ Law } & -0.0093 & -0.0060 & 0.0153 \\
\hline & $(0.0089)$ & $(0.0078)$ & $(0.0112)$ \\
\hline \multirow[t]{2}{*}{ Social science } & -0.0017 & $0.0191^{* * * *}$ & $-0.0175^{* *}$ \\
\hline & $(0.0066)$ & $(0.0056)$ & $(0.0083)$ \\
\hline \multirow[t]{2}{*}{ Technology/engineering } & $-0.0213^{* * *}$ & $-0.0333^{* * *}$ & $0.0547^{* * *}$ \\
\hline & $(0.0074)$ & $(0.0083)$ & $(0.0104)$ \\
\hline \multirow[t]{2}{*}{ Health and welfare } & $-0.0548^{* * * *}$ & $-0.0197^{* *}$ & $0.0746^{* * * *}$ \\
\hline & $(0.0095)$ & $(0.0081)$ & $(0.0115)$ \\
\hline \multirow[t]{2}{*}{ Medium intake grades } & $-0.0140^{* *}$ & $-0.0089^{*}$ & $0.0229^{* * * *}$ \\
\hline & $(0.0060)$ & $(0.0050)$ & $(0.0074)$ \\
\hline \multirow[t]{2}{*}{ High intake grades } & $-0.0210^{* * *}$ & $-0.0282^{* * *}$ & $0.0491^{* * * *}$ \\
\hline & $(0.0061)$ & $(0.0055)$ & $(0.0078)$ \\
\hline \multirow[t]{2}{*}{ Both parents higher education } & 0.0001 & $-0.0132^{* *}$ & 0.0131 \\
\hline & $(0.0064)$ & $(0.0055)$ & $(0.0080)$ \\
\hline \multirow[t]{2}{*}{ One parent higher education } & 0.0019 & -0.0082 & 0.0063 \\
\hline & $(0.0069)$ & $(0.0058)$ & $(0.0085)$ \\
\hline \multirow[t]{2}{*}{ Low educated parents } & -0.0078 & 0.0069 & 0.0009 \\
\hline & $(0.0081)$ & $(0.0065)$ & $(0.0099)$ \\
\hline \multirow[t]{2}{*}{ Lived outside Norway at age 17} & $0.0399^{* * * *}$ & $0.0245^{* * * *}$ & $-0.0644^{* * *}$ \\
\hline & $(0.0095)$ & $(0.0090)$ & $(0.0127)$ \\
\hline \multirow{2}{*}{ Non-Western immigrant } & $0.0560^{* * * *}$ & $0.0207^{* *}$ & $-0.0767^{* * * *}$ \\
\hline & $(0.0096)$ & $(0.0092)$ & $(0.0129)$ \\
\hline \multirow[t]{2}{*}{ Western immigrant } & 0.0154 & -0.0108 & -0.0046 \\
\hline & $(0.0124)$ & $(0.0122)$ & $(0.0168)$ \\
\hline \multirow[t]{2}{*}{ Second-generation immigrant } & 0.0229 & 0.0175 & $-0.0404^{* *}$ \\
\hline & $(0.0157)$ & $(0.0124)$ & $(0.0194)$ \\
\hline \multirow[t]{2}{*}{ ISM* Medium intake grades } & -0.0083 & 0.0123 & -0.0041 \\
\hline & $(0.0119)$ & $(0.0102)$ & $(0.0149)$ \\
\hline \multirow[t]{2}{*}{ ISM* High intake grades } & $-0.0305^{* *}$ & 0.0048 & $0.0257^{*}$ \\
\hline & $(0.0120)$ & $(0.0109)$ & $(0.0153)$ \\
\hline \multicolumn{4}{|c|}{$\begin{array}{l}\text { Also included are controls for age, sex, cohort, relevant and non-relevant work before graduation, where th } \\
\text { effects are very similar to those in Table } 4 .\end{array}$} \\
\hline$N$ & 15,123 & & \\
\hline Cragg \& Uhler's R2 (Pseudo R2) & 0.172 & & \\
\hline
\end{tabular}

a Significant at level $p<0.1$. **Significant at level $p<0.05$. ***Significant at level $p<0.01$

Results of multinomial logistic regressions (average marginal effects), including interaction effects of intake grades and ISM experience. Standard errors in parentheses

ISM experience on the labour market adaptation exists for graduates with low parental education level.

Regarding immigrant background, the results are similar (Table 7). The interaction effect of ISM and being a non-Western immigrant is non-significant. This gives no support to H5, which states that a positive effect of ISM experience on the labour market adaptation should exist for graduates with a non-Western immigrant background. 
Table 6 The probability of being unemployed, having involuntary irrelevant work or having relevant work

\begin{tabular}{|c|c|c|c|}
\hline ISM experience (stud abroad) & $\begin{array}{l}\text { Unemployed } \\
-0.0065\end{array}$ & $\begin{array}{l}\text { Irrelevant work } \\
-0.0044\end{array}$ & $\begin{array}{l}\text { Relevant work } \\
0.0109\end{array}$ \\
\hline \multirow[t]{2}{*}{ Pedagogy } & $(0.0142)$ & $(0.0111)$ & $(0.0172)$ \\
\hline & $-0.0607^{* * *}$ & $-0.0577^{* * * *}$ & $0.1184^{* * *}$ \\
\hline \multirow[t]{2}{*}{ Humanities and arts } & $(0.0105)$ & $(0.0108)$ & $(0.0137)$ \\
\hline & 0.0011 & $0.0325^{* * *}$ & $-0.0335^{* * *}$ \\
\hline \multirow[t]{2}{*}{ Business \& administration } & $(0.0072)$ & $(0.0059)$ & $(0.0089)$ \\
\hline & $-0.0286^{* * * *}$ & $-0.0259^{* * *}$ & $0.0545^{* * * *}$ \\
\hline \multirow[t]{2}{*}{ Law } & $(0.0073)$ & $(0.0070)$ & $(0.0094)$ \\
\hline & -0.0096 & -0.0060 & 0.0156 \\
\hline \multirow[t]{2}{*}{ Social science } & $(0.0089)$ & $(0.0078)$ & $(0.0112)$ \\
\hline & -0.0016 & $0.0193^{* * *}$ & $-0.0177^{* *}$ \\
\hline \multirow[t]{2}{*}{ Technology/engineering } & $(0.0066)$ & $(0.0056)$ & $(0.0083)$ \\
\hline & $-0.0217^{* * *}$ & $-0.0334^{* * *}$ & $0.0551^{* * * *}$ \\
\hline \multirow[t]{2}{*}{ Health and welfare } & $(0.0074)$ & $(0.0083)$ & $(0.0104)$ \\
\hline & $-0.0543^{* * *}$ & $-0.0199^{* *}$ & $0.0742^{* * * *}$ \\
\hline \multirow[t]{2}{*}{ Medium intake grades } & $(0.0095)$ & $(0.0081)$ & $(0.0115)$ \\
\hline & $-0.0154^{* * * *}$ & -0.0060 & $0.0213^{* * * *}$ \\
\hline \multirow[t]{2}{*}{ High intake grades } & $(0.0052)$ & $(0.0044)$ & $(0.0065)$ \\
\hline & $-0.0284^{* * *}$ & $-0.0274^{* * *}$ & $0.0558^{* * * *}$ \\
\hline \multirow[t]{2}{*}{ Both parents higher education } & $(0.0054)$ & $(0.0049)$ & $(0.0069)$ \\
\hline & 0.0024 & $-0.0132^{* *}$ & 0.0108 \\
\hline \multirow{2}{*}{ One parent higher education } & $(0.0072)$ & $(0.0063)$ & $(0.0091)$ \\
\hline & -0.0003 & -0.0097 & 0.0100 \\
\hline \multirow[t]{2}{*}{ Low educated parents } & $(0.0078)$ & $(0.0067)$ & $(0.0097)$ \\
\hline & -0.0120 & 0.0098 & 0.0022 \\
\hline \multirow[t]{2}{*}{ Lived outside Norway at age 17} & $(0.0090)$ & $(0.0072)$ & $(0.0110)$ \\
\hline & $0.0400^{* * * *}$ & $0.0247^{* * * * *}$ & $-0.0647^{* * * *}$ \\
\hline \multirow[t]{2}{*}{ Non-Western immigrant } & $(0.0095)$ & $(0.0090)$ & $(0.0127)$ \\
\hline & $0.0576^{* * * *}$ & $0.0208^{* *}$ & $-0.0784^{* * * *}$ \\
\hline \multirow[t]{2}{*}{ Western immigrant } & $(0.0095)$ & $(0.0091)$ & $(0.0129)$ \\
\hline & 0.0159 & -0.0109 & -0.0051 \\
\hline \multirow[t]{2}{*}{ Second-generation immigrant } & $(0.0124)$ & $(0.0122)$ & $(0.0168)$ \\
\hline & 0.0224 & 0.0175 & $-0.0399^{* *}$ \\
\hline \multirow{2}{*}{ ISM* Both parents higher education } & $(0.0157)$ & $(0.0124)$ & $(0.0194)$ \\
\hline & -0.0094 & 0.0000 & 0.0093 \\
\hline \multirow[t]{2}{*}{ ISM* One parent higher education } & $(0.0156)$ & $(0.0126)$ & $(0.0191)$ \\
\hline & 0.0081 & 0.0060 & -0.0142 \\
\hline \multirow[t]{3}{*}{ ISM* Low educated parents } & $(0.0168)$ & $(0.0136)$ & $(0.0206)$ \\
\hline & 0.0219 & -0.0159 & -0.0061 \\
\hline & $(0.0202)$ & $(0.0164)$ & $(0.0248)$ \\
\hline \multicolumn{4}{|c|}{$\begin{array}{l}\text { Also included are controls for age, sex, cohort, relevant and non-relevant work before graduation, where th } \\
\text { effects are very similar to those in Table } 4\end{array}$} \\
\hline$N$ & 15,123 & 15,123 & 15,123 \\
\hline Cragg \& Uhler's R2 (Pseudo R2) & 0.172 & & \\
\hline
\end{tabular}

a Significant at level $p<0.1$. **Significant at level $p<0.05$. ***Significant at level $p<0.01$

Results of multinomial logistic regressions (average marginal effects), including interaction effects of parental education level and ISM experience. Standard errors in parentheses

In summary, we find very few heterogeneous effects. Business and administration graduates, i.e. graduates who mainly find work in the private sector benefit somewhat more from ISM in terms of reduced risk of holding irrelevant work, whereas we found no significant effects of studying abroad among graduates in the other fields of study. Graduates with high intake grades benefit more from ISM experience whereas no effects of ISM are shown for those with low or medium intake grades. 
All the independent variables, except for 'work experience before graduation' are features which were present before enrolment into higher education. Work experience can occur before as well as after the (possible) ISM. In additional analyses, we examined whether the inclusion of the control for such experience were significant for the difference between graduates with and without ISM experience and found that it was not. Although ISM graduates have such experience less frequently, the inclusion of this control is of very little significance for the effects of studying abroad.

Table 7 The probability of being unemployed, having involuntary irrelevant work or having relevant work

\begin{tabular}{|c|c|c|c|}
\hline ISM experience (stud abroad) & $\begin{array}{l}\text { Unemployed } \\
-0.0063\end{array}$ & $\begin{array}{l}\text { Irrelevant work } \\
-0.0048\end{array}$ & $\begin{array}{l}\text { Relevant work } \\
0.0110^{*}\end{array}$ \\
\hline \multirow[t]{2}{*}{ Pedagogy } & $(0.0051)$ & $(0.0043)$ & $(0.0063)$ \\
\hline & $-0.0608^{* * *}$ & $-0.0577^{* * * *}$ & $0.1185^{* * *}$ \\
\hline \multirow[t]{2}{*}{ Humanities and arts } & $(0.0105)$ & $(0.0108)$ & $(0.0137)$ \\
\hline & 0.0013 & $0.0324^{* * * *}$ & $-0.0337^{* * *}$ \\
\hline \multirow[t]{2}{*}{ Business \& administration } & $(0.0072)$ & $(0.0059)$ & $(0.0089)$ \\
\hline & $-0.0283^{* * *}$ & $-0.0260^{* * *}$ & $0.0543^{* * *}$ \\
\hline \multirow[t]{2}{*}{ Law } & $(0.0073)$ & $(0.0070)$ & $(0.0094)$ \\
\hline & -0.0097 & -0.0061 & 0.0158 \\
\hline \multirow[t]{2}{*}{ Social science } & $(0.0089)$ & $(0.0078)$ & $(0.0112)$ \\
\hline & -0.0017 & $0.0193^{\text {**** }}$ & $-0.0176^{* *}$ \\
\hline \multirow[t]{2}{*}{ Technology/engineering } & $(0.0066)$ & $(0.0056)$ & $(0.0083)$ \\
\hline & $-0.0222^{* * *}$ & $-0.0333^{* * *}$ & $0.0555^{* * *}$ \\
\hline \multirow[t]{2}{*}{ Health and welfare } & $(0.0074)$ & $(0.0083)$ & $(0.0104)$ \\
\hline & $-0.0544^{* * *}$ & $-0.0199^{* *}$ & $0.0742^{* * * *}$ \\
\hline \multirow[t]{2}{*}{ Medium intake grades } & $(0.0095)$ & $(0.0081)$ & $(0.0115)$ \\
\hline & $-0.0155^{* * *}$ & -0.0060 & $0.0215^{* * *}$ \\
\hline \multirow[t]{2}{*}{ High intake grades } & $(0.0052)$ & $(0.0044)$ & $(0.0065)$ \\
\hline & $-0.0288^{* * *}$ & $-0.0275^{* * *}$ & $0.0562^{* * * *}$ \\
\hline \multirow[t]{2}{*}{ Both parents higher education } & $(0.0054)$ & $(0.0049)$ & $(0.0069)$ \\
\hline & -0.0004 & $-0.0131^{* *}$ & $0.0135^{*}$ \\
\hline \multirow{2}{*}{ One parent higher education } & $(0.0064)$ & $(0.0055)$ & $(0.0080)$ \\
\hline & 0.0017 & -0.0081 & 0.0064 \\
\hline \multirow[t]{2}{*}{ Low educated parents } & $(0.0069)$ & $(0.0058)$ & $(0.0085)$ \\
\hline & -0.0082 & 0.0070 & 0.0012 \\
\hline \multirow[t]{2}{*}{ Lived outside Norway at age 17} & $(0.0081)$ & $(0.0065)$ & $(0.0099)$ \\
\hline & $0.0397^{* * *}$ & $0.0246^{* * * *}$ & $-0.0643^{* * *}$ \\
\hline \multirow[t]{2}{*}{ Non-Western immigrant } & $(0.0095)$ & $(0.0091)$ & $(0.0128)$ \\
\hline & $0.0596^{* * *}$ & $0.0212^{* * *}$ & $-0.0808^{* * *}$ \\
\hline \multirow[t]{2}{*}{ Western immigrant } & $(0.0100)$ & $(0.0096)$ & $(0.0136)$ \\
\hline & 0.0169 & -0.0110 & -0.0059 \\
\hline \multirow[t]{2}{*}{ Second-generation immigrant } & $(0.0124)$ & $(0.0122)$ & $(0.0168)$ \\
\hline & 0.0231 & 0.0174 & $-0.0404^{* *}$ \\
\hline \multirow[t]{3}{*}{ ISM* Non-Western immigrant } & $(0.0157)$ & $(0.0124)$ & $(0.0194)$ \\
\hline & -0.0136 & -0.0014 & 0.0151 \\
\hline & $(0.0210)$ & $(0.0218)$ & $(0.0299)$ \\
\hline
\end{tabular}

Also included are controls for age, sex, cohort, relevant and non-relevant work before graduation, where the effects are very similar to those in Table 4
$N$
15,123
15,123
15,123
Cragg \& Uhler's R2 (Pseudo R2)
0.171

a Significant at level $p<0.1$. **Significant at level $p<0.05$. ***Significant at level $p<0.01$

Results of multinomial logistic regressions (average marginal effects), including interaction effect of being a nonWestern immigrant and ISM experience. Standard errors in parentheses 


\section{Discussion}

This article has investigated the effects of short-term ISM on the transition from higher education to the labour market for master graduates in Norway. Two indicators of maladaptation were used as follows: unemployment and skills mismatch in the form of involuntary irrelevant work. When controlling for relevant background variables, including fields of study, we generally did not find significant effects of ISM on the likelihood of being unemployed or holding involuntary irrelevant work. However, for two subgroups, i.e. graduates with high intake scores and graduates in business in administration, significant interaction effects of ISM do exist. Regarding grades, and contrary to the findings of Liwiński (2016), we do not find that graduates with low intake grades benefit more from a study period abroad; rather, we find that those with high intake grades ('all other things being equal') seem to do so. Regarding fields of study, ISM reduces to some extent the risk of labour market marginalization for one group of professionals, i.e. graduates in business and administration. This field mainly prepares graduates for the private sector, and the finding may be interpreted in such a way that experience from abroad has a stronger signalling effect in the private sector than in public sector or simply that experience from abroad is in higher demand in the business and administration field than in others. For technology graduates, who also mainly end up in the private sector, no significant effect of studying abroad was found.

Our results provide limited support to the assumption derived from Waibel et al. (2018), Di Pietro (2015) and others that graduates who are least likely to study abroad are those who particularly benefit from ISM. Graduates with low intake grades do not benefit more. Neither do we find that other groups with a low probability to study abroad, such as graduates with low educated parents, graduates in low ISM propensity fields and non-Western immigrant graduates, benefit more from ISM than others. Non-Western immigrants generally face more challenges in the labour market, but ISM experience does not alter this.

For graduates in health and welfare, and pedagogy — who have a low probability of engaging in ISM - no significant effects of ISM were observed. This also applies to graduates in the social sciences (who have high probability of engaging in ISM). Our results indicate that one group with a high probability of engaging in ISM (graduates in business and administration) benefit most. This is not in accordance with the previous findings mentioned above, which indicated that graduates who are least likely to acquire ISM experience are those who particularly benefit from ISM. Our findings also stand in contrast to the results of Waibel et al. (2018), which indicated that graduates in generic fields benefit more than graduates in vocational-oriented fields. We consider business and administration programmes more vocational than generic; further, we find no significant effect of studying abroad in generic fields such as social science, natural science and the humanities.

Other factors, such as intake grades, business cycles, fields of study and immigrant background, have a much larger impact on labour market prospects 6 months after graduation than ISM experience. Why are the effects of studying abroad overall so small? Some possible explanations are suggested in the following paragraphs.

The demand for master graduates in the Norwegian labour market has traditionally been high. When the competition for jobs is not too harsh, the signalling effect of education abroad may be weaker than in a situation with fierce competition. However, in general, we do not find that ISM graduates are less affected than other graduates when the labour market situation was worsened, as in 2015 and 2017. Still, for one group, the descriptive, uncontrolled results may indicate this. Technology graduates with ISM experience had better labour market prospects than graduates without such experience in 2017. This year, as well as in 2015, the unemployment rate was higher 
than usual among technology graduates in Norway. The finding for the technology graduates with ISM experience in 2017 can possibly be interpreted in such a way that the signalling effect of education abroad is stronger in a situation with fierce competition.

Our results fit well with the findings of Jacobs et al. (2019) as well as the Erasmus Impact Study (European Commission 2014), which show that effects of ISM are less important in Northern Europe than in some other parts of Europe. This may be due to the public sector being quite large in the Nordic countries and that larger numbers of graduates are recruited to this sector. Another explanation can be that Norway and some other Nordic countries have long traditions for sending students abroad; hence, a relatively high proportion of the academic labour force has this kind of experience. This implies that ISM experience is not unique, and the signalling effect may consequently be weaker. This is in accordance with Van Mol (2017), who finds that experience from abroad is considered less important by Norwegian recruiters than by recruiters in many other countries, and a recent survey among Norwegian employers confirms that experience from abroad is not seen as a very important recruitment criterion (Støren et al. 2019).

The small effects of ISM may also be related to the time of measurement. Six months after graduation is very early in graduates' career, and differences between graduates with and without mobility experience may emerge more strongly at a later stage, in line with the findings of Kratz and Netz (2018). We note that the Erasmus Impact Study also found that effects were smaller shortly after graduation than some years later.

A range of studies has shown that students who engage in ISM report to develop language proficiency and cultural skills (see e.g. Murphy-Lejeune 2002; Krzaklewska and Krupnik 2005; Stronkhorst 2005; Jones 2013; European Union 2016) and experience a personal growth (e.g. Murphy-Lejeune 2002; Brooks and Waters 2011; European Commission 2014). Such competencies may add to the graduate's human and social capital but are not necessarily transformed into enhanced employment prospects. In line with Yorke (2006), employability is a probabilistic concept that does not necessarily convert into employment. This means that students may develop skills while studying abroad that are perceived as enriching, but not necessarily rewarded in the labour market.

Further, it has been questioned to what extent short-term ISM really improves such skills (Stronkhorst 2005), and the added value of a few months abroad may be limited. Further, not all forms of human and social capital are transferable across national borders. Even in an era of increased global interconnectedness, some competencies and skills may be mainly countryspecific rather than transnational (Chiswick and Miller 2009). Examples of such are certain languages and knowledge of national laws and regulations. Country specificity may also apply to social and professional networks - connections that may be important regarding obtaining employment. Still, a lack of relevant country-specific human capital is probably more of a challenge for free-movers (students who undertake a full degree abroad), compared with the graduates in this study who have undertaken the major part of their education domestically.

\section{Strengths and limitations of the study}

This study has several strengths: Time series data including several cohorts with a high response rate are analysed, and we have made comparisons of graduates participating in different study programmes and belonging to different social groups. Hence, this represents a solid empirical contribution to research on labour market effects of short-term ISM, though we cannot claim that results are transferable across countries. 
Although the topic for examination here is the possible impact of ISM on employment and mismatch, it should be emphasized that ISM also can have other positive effects than reducing labour market mismatch. It may add to the students' experiences in more ways than the professional skills acquired through the education itself, e.g. by enhancing language proficiency and cross-cultural understanding (cf. Discussion section).

We have focused on the labour market adaptation in terms of unemployment and involuntary irrelevant work. Other indicators of labour market outcomes would also be relevant to investigate such as wages, broader definitions of over-education and aspects of horizontal career. There are several reasons why such indicators are not included in our study. Regarding wages, such analyses may be more interesting later in the career than 6 months after graduation. Regarding wider definitions of over-education, we consider this as a less precise measure of labour market marginalization 6 months after graduation, because the proportion over-educated for the job is quite high among most groups of master graduates. Further, information about the country and institution where the education abroad is undertaken is not available in our data set.

\section{Policy implications}

The results challenge the widespread notion that ISM enhances employment prospects. We find that ISM generally has little impact on the transition from higher education to work in Norway, compared with other factors, although some groups seem to benefit slightly more than others. This does not imply that ISM should not be encouraged but points towards factors other than enhanced employment prospects which should be advanced as arguments for engaging in ISM.

Acknowledgements We thank NIFU researcher Asgeir Skålholt for technical assistance regarding running the regression analyses in STATA.

Funding information Open Access funding provided by OsloMet - Oslo Metropolitan University. This research is funded by the Norwegian Research Council, project number 283545.

\section{Compliance with ethical standards}

Conflict of interest The authors declare that they have no conflict of interest.

Research ethics The results presented in this article do not allow for deductive disclosure of the survey participants' identities. Participation in the survey was voluntary and participants' confidentiality was protected, and personal identifying information is removed from the dataset.. The data collection is approved by Norwegian Data Protection Services (NSD).

\section{Appendix 1. Description of independent variables}

\section{ISM experience}

The graduates were asked: 'Did you have any period(s) of study abroad lasting for at least one semester as part of the education (including the lower/first degree) you completed in the spring of .....?' 


\section{Parental education level}

The educational level of the graduate's parents is grouped into four categories as follows: (1) Both parents have higher education; (2) one of the parents has higher education; (3) both parents have medium education level (upper secondary education), used as the reference category in the regression; and (4) low parental education level (both parents have low education or one has low and one has medium education level.

\section{Immigrant backgrounds}

Immigrants with non-Western background are born in Asia, Africa, Latin-America or Eastern Europe, except East-European countries that are members of European Union, ${ }^{5}$ and both parents are born outside Norway. The remaining immigrant graduates are defined as having Western background. Second-generation immigrants (a smaller group) are born in Norway, but both parents were born abroad.

\section{Residence at the age of 17}

Graduates were asked 'what was your county of residence at the age of 17?' If it was abroad, they were asked to indicate this. More than $80 \%$ who did not reside in Norway at the age of 17 were immigrants. Among the immigrants, the proportion that resided outside Norway at this age was $46 \%$ among those with non-Western background and $35 \%$ among with Western background.

\section{Fields of study}

The graduate's education is coded in accordance with Norwegian Standard Classification of Education (Statistics Norway 2017). The first two of the six digits in this classification system are used, indicating level (bachelor or master - the first digit) and broad fields (the second digit). For some fields, the third digit for narrow field is also used, for example, to distinguish law from social science, and sports and physical education from health and welfare which otherwise belong to the same broad fields. In addition, the field 'natural sciences and technical subjects' is divided into two groups as follows: master of technology (graduate engineering) and natural science.

\section{Work experience before graduation}

Graduates were asked about previous work experience. This may have taken place before the study programme started, parallel to studies or as a break in studies. The majority answered that working experience occurred parallel to studying. The graduates were also asked whether this work was relevant to the study programme. We have distinguished between those who report having previous relevant working experience and those who have not.

\footnotetext{
${ }^{5}$ Norway is a member of the European Economic Area, and EU citizens have the same right to work in Norway as in EU countries.
} 


\section{Intake grades}

The graduates were asked: 'What was your average grade from upper secondary school?' The scale is 1 to 7 , referring to grades from 2 to 6 (highest is best). The pre-coded options were as follows: Value $1=$ Lower than 3 ; value $2=3.0-3.4$; value $3=3.5-3.9$; value $4=4.0-4.4$; value $5=4.5-4.9$; value $6=5.0-5.4$; and value $7=5.5$ or higher. The group with 'low grades' in Table 5 has grades below value 4 (28.3\% of the sample). The group with medium grades has value 5 (i.e. grades between 4.5 and 4.9) (35.4\% of the sample), and the group with high grades has value 6 or 7 (i.e. grades between 5 and 6) (36.3\% of the sample).

\section{Appendix 2}

Table 8 Mean sample values of independent variables included in the regressions

\begin{tabular}{|c|c|c|c|}
\hline & All & No study abroad & Study abroad \\
\hline Study abroad (ISM experience) & 0.251 & & \\
\hline Female & 0.611 & 0.617 & 0.594 \\
\hline Age & 30.9 & 32.1 & 27.3 \\
\hline 2007 & 0.175 & 0.176 & 0.171 \\
\hline 2009 & 0.137 & 0.136 & 0.138 \\
\hline 2011 & 0.151 & 0.148 & 0.161 \\
\hline 2013 & 0.150 & 0.150 & 0.151 \\
\hline 2015 & 0.186 & 0.181 & 0.203 \\
\hline 2017 & 0.201 & 0.209 & 0.175 \\
\hline Low intake grades & 0.283 & 0.309 & 0.206 \\
\hline Medium intake grades & 0.354 & 0.359 & 0.336 \\
\hline High intake grades & 0.363 & 0.332 & 0.457 \\
\hline Humanities and arts & 0.125 & 0.127 & 0.121 \\
\hline Pedagogy and teacher training & 0.114 & 0.139 & 0.041 \\
\hline Social science & 0.163 & 0.143 & 0.224 \\
\hline Law & 0.075 & 0.076 & 0.075 \\
\hline Business and administration & 0.150 & 0.126 & 0.223 \\
\hline Natural science & 0.145 & 0.150 & 0.131 \\
\hline Technology (graduate engineering) & 0.108 & 0.098 & 0.138 \\
\hline Health and welfare & 0.118 & 0.142 & 0.048 \\
\hline Relevant work before graduation & 0.594 & 0.625 & 0.503 \\
\hline Other, not relevant work before graduation & 0.230 & 0.220 & 0.259 \\
\hline Lived outside Norway at age 17 & 0.064 & 0.071 & 0.043 \\
\hline Without immigrant background & 0.914 & 0.906 & 0.941 \\
\hline Non-Western immigrant & 0.045 & 0.053 & 0.020 \\
\hline Western immigrant & 0.028 & 0.030 & 0.023 \\
\hline Second-generation immigrants & 0.013 & 0.011 & 0.016 \\
\hline Both parents have higher education & 0.446 & 0.404 & 0.572 \\
\hline One of the parents has higher education & 0.261 & 0.269 & 0.239 \\
\hline Both parents have medium education level & 0.126 & 0.135 & 0.099 \\
\hline $\begin{array}{l}\text { Both parents have low education, or one with } \\
\text { medium and one with low }\end{array}$ & 0.166 & 0.192 & 0.089 \\
\hline$N$ & 15,213 & 11,439 & 3774 \\
\hline
\end{tabular}


Table 9 Unemployment in Norway 2001-2017

\begin{tabular}{llll}
\hline & $\begin{array}{l}\text { Unemployed, \% of the labour } \\
\text { force of fresh graduates }\end{array}$ & $\begin{array}{l}\text { Unemployed, \% of the } \\
\text { general labour force }\end{array}$ & $\begin{array}{l}\text { Unemployed, \% of the general labour } \\
\text { force with higher education }\end{array}$ \\
\hline 2001 & 6.9 & 3.5 & 2.4 \\
2003 & 11.1 & 4.5 & 3 \\
2005 & 8.1 & 4.6 & 2.6 \\
2007 & 3.9 & 2.5 & 1.6 \\
2009 & 6.1 & 3.2 & 1.6 \\
2011 & 5.9 & 3.3 & 1.7 \\
2013 & 6.8 & 3.5 & 2 \\
2015 & 8.7 & 4.4 & 2.6 \\
2016 & $:$ & 4.7 & 3.1 \\
2017 & 7.9 & 4.2 & 2.4 \\
\hline
\end{tabular}

Means unknown, because no graduate survey

Sources: Statistics Norway, Statbank; NIFU Graduate surveys

Table 10 Proportion in the private sector

Share of employed graduates who work in the private sector. Per cent ${ }^{\mathrm{a}}$

Humanities and arts

Pedagogy and teacher training

Social science

Law

Business and administration

Natural science

Technology (graduate engineering)

Health and welfare
39.4
13.9
39.3
48.6
71.8
53.5
80.8
30.2

a Number base: graduates 2007-2017 included in the regression analyses, who are employed

Open Access This article is licensed under a Creative Commons Attribution 4.0 International License, which permits use, sharing, adaptation, distribution and reproduction in any medium or format, as long as you give appropriate credit to the original author(s) and the source, provide a link to the Creative Commons licence, and indicate if changes were made. The images or other third party material in this article are included in the article's Creative Commons licence, unless indicated otherwise in a credit line to the material. If material is not included in the article's Creative Commons licence and your intended use is not permitted by statutory regulation or exceeds the permitted use, you will need to obtain permission directly from the copyright holder. To view a copy of this licence, visit http://creativecommons.org/licenses/by/4.0/.

\section{References}

Ai, C., \& Norton, E. C. (2003). Interaction terms in logistic and probit models. Economics Letters, 80(1), 123129.

Arrow, K. (1973). Higher education as a filter. Journal of Public Economics, 2(3), 193-216.

Blanck, D., \& Börjesson, M. (2008). Transnational strategies in higher education and cultural fields: The case of the United States and Sweden in the 20th century. American Studies in Scandinavia, 40(1-2), 80-89.

Blumenthal, P., Goodwin, C., Smith, A., \& Teichler, U. (1996). Academic mobility in a changing world: Regional and global trends. London: Jessica Kingsley. 
Brand, J. E., \& Xie, Y. (2010). Who benefits most from college? Evidence for negative selection in heterogeneous economic returns to higher education. American Sociological Review, 75(2), 273-302.

Brooks, R., \& Waters, J. (2011). Student Mobilities, migration and internationalization of higher education. Basingstoke: Palgrave Macmillan.

Chiswick, B., \& Miller, P. W. (2009). The international transferability of immigrants' human capital. Economics of Education Review, 28(2), 162-169.

Connelly, B. L., Certo, S. T., Ireland, R. D., \& Reutzel, C. R. (2011). Signaling theory: A review and assessment. Journal of Management, 37(1), 39-67.

de Wit, H. (2002). Internationalization of higher education in the United States of America and Europe: A historical, comparative and conceptual analysis. Westport, CT: Greenwood.

de Wit, H. (2013). Internationalisation, meaning and rationales. In H. de Wit (Ed.), An introduction to higher education internationalisation (pp. 13-46). Milan: Università Cattolica del Sacro Curore.

Di Pietro, G. (2015). Do study abroad programs enhance the employability of graduates? Education Finance and Policy, 10(2), 223-243.

European commission (2016). The Erasmus Impact Study. Regional analysis. Luxemburg: European Union.

European Commission. (2018). Mobility and cross-border cooperation. http://ec.europa. eu/education/policy/higher-education/mobility-cbc_en. Accessed March 20th 2018.

European Commission. (2017). From Erasmus to Erasmust: a story of 30 years. Brussels: European Commission. http://europa.eu/rapid/press-release_MEMO-17-83_en.htm. Accessed March 20th 2018.

European Commission. (2014). The Erasmus impact study. A comparative analysis of the effects of Erasmus on the personality, skills and career of students of European regions and selected countries. Luxemburg: European Commission.

Frickey, J., Murdoch, J., \& Primon, J. L. (2006). From higher education to employment. Inequalities among ethnic backgrounds in France. European Education: A Journal of Issues and studies, 37(4), 61-74.

Gerhards, J., \& Hans, S. (2013). Transnational human capital, education and social inequality. Analyses of International Student Exchange. Zeitschrift für Soziologie, 42(2), 99-117.

Heath, A. F., Rothon, C., \& Kilpi, E. (2008). The second-generation in Western Europe: Education, unemployment, and occupational attainment. Annual Review of Sociology, 34, 211-235.

Humburg, M., \& van der Velden, R. (2015). Skills and the graduate recruitment process: Evidence from two discrete choice experiments. Economics of Education Review, 49, $24-41$.

Jacob, M., Kühhirt, M., \& Rodriguez, M. (2019). Labour market returns to graduates' international experience: Exploring cross-country variations in Europe. European Sociological Review, 35(4), 491-505.

Jones, E. (2013). Internationalisation and employability: The role of intercultural experiences in the development of transferable skills. Public Money and Management, 33(2), 95-104.

King, R., Findlay, A., \& Ahrens, J. (2010). International student mobility literature review. In Report to HEFCE, and co-funded by the British Council, UK National Agency for Erasmus. London: Higher education funding Council for England (HEFCE).

Knight, J. (2004). Internationalization remodelled: Definition, approaches and rationales. Journal of Studies in International Education, 8(1), 5-31.

Kratz, F., \& Netz, N. (2018). Which mechanisms explain monetary returns to international student mobility. Studies in Higher Education, 43(2), 375-400.

Krzaklewska, E., \& Krupnik, S. (2005). The experience of studying abroad for exchange students in Europe. Brussels: Erasmus Student Network.

Liwiński, J. (2016). Does it pay to study abroad? Evidence from Poland. Working paper no. 25/2016. University of Warsaw, Faculty of Economic Sciences.

Ministry of Education. (2017). Tilstandsrapport for høyere utdanning [Status report for higher education]. https:/www.regjeringen.no/no/dokumenter/tilstandsrapport-for-hoyere-utdanning-2017/id2552473/.

Merton, R. K. (1968). The Matthew effect in science. Science, 159(3810), 55-63.

Ministry of Education and research. (2009). Internasjonalisering av utdanning [internationalisation of education] white paper no 14 2008-2009. Oslo: Ministry of Education and Research.

Mood, C. (2010). Logistic regression: Why we cannot do what we think we can do, and what we can do about it. European Sociological Review, 26(1), 67-82.

Murphy-Lejeune, E. (2002). Student mobility and narrative in Europe. London: Routledge.

OECD. (2019). Education at a glance. Paris: OECD.

$\mathrm{OECD}$ /European Union. (2015). Labour market outcomes of immigrants. In 'Indicators of Immigrant Integration 2015 - settling In'. (https://www.oecd-ilibrary.org/social-issues-migration-health/indicators-of-immigrantintegration-2015-settling-in_9789264234024-en).

Oosterbeek, H., \& Webbink, D. (2011). Does studying abroad induce a brain drain? Economica, 78(310), 347366. 
Otero, M. S. (2008). The socio-economic background of ERASMUS students: A trend towards wider inclusion? International Review of Education, 54, 135-154.

Parey, M., \& Waldinger, F. (2010). Studying abroad and the effect on international labour market mobility: Evidence from the introduction of ERASMUS. The Economic Journal, 121, 194-222.

Petzold, K. (2017). The role of international student mobility in hiring decisions. A vignette experiment among German employers. Journal of Studies in International Education, 30(8), 893-911.

Spence, M. (1973). Job Market Signalling. The Quarterly Journal of Economics, 87(3), 355-374.

Statistics Norway. (2017). Norwegian Standard Classification of Education 2016. https://www.ssb. no/en/utdanning/artikler-og-publikasjoner/norwegian-standard-classification-of-education-2016.

Stronkhorst, R. (2005). Learning outcomes of international mobility at two Dutch institutions of higher education. Journal of Studies in International Education, 9(4), 292-315.

Støren, L. A., \& Wiers-Jenssen, J. (2010). Foreign diploma versus immigrant background: Determinants of labour market success or failure? Journal of Studies in International Education, 14(1), 29-49.

Støren, L. A., \& Arnesen, C. Å. (2011). Winners and losers. In Allen \& V. der Velden (Eds.), The Flexible Professional in the Knowledge Society. Dordrecht: Springer.

Støren, L. A., \& Arnesen, C. A. (2016). Skills utilisation at work, the quality of the study programme and fields of study. Quality in Higher Education, 16(3), 297-313.

Støren, L. A., \& Wiers-Jenssen, J. (2016). Transition from higher education to work: Are master graduates increasingly over-educated for their jobs? Tertiary Education and Management, 22(2), 134-148.

Støren, L. A., Reiling, R. B., Skjelbred, S.-E., Ulvestad, M. E., Carlsten, T. C., \& Olsen, D. S. (2019). Utdanning for arbeidslivet. Arbeidsgivers forventninger til og erfaringer med nyutdannede fra universiteter, høgskoler og fagskoler. [Education for working life]. Report 3. Oslo: NIFU.

Teichler, U., \& Janson, K. (2007). The professional value of temporary study in another European country: Employment and work of former ERASMUS students. Journal of Studies in International Education, 11(34), 486-495.

Teichler, U. (2015). The impact of temporary study abroad. In: Mitchell, R. Tracy-Venturan, N., \& McManus, K. (eds.): Social interaction, identity and language learning during residence abroad. Eurosla Monographs Series, 4(2015), 15-32.

Thune, T., \& Støren, L. A. (2015). Study and labour market effects of graduate students' interaction with work organisations during education: A cohort study. Education + Training, 57(7), 702-722.

Van Mol, C. (2017). Do employers value international study and internships? A comparative analysis of 31 countries. Geoforum, 78, 52-60.

vand der Wende, M. (1997), 'Missing links. The relationship between National Policies for Internationalisation and those for Higher Education in general'. In Kälvemark and van der Wende. National Policies for the Internationalisation of Higher Education in Europe. Stockholm: National agency of Higher Education.

Verhaest, D., \& van der Velden, R. (2012). Cross-country differences in graduate Overeducation. European Sociological Review, 29(3), 642-653.

Waibel, S., Rüger, H., Ette, A., \& Sauer, L. (2017). Career consequences of transnational educational mobility: A systematic literature review. Educational Research Review, 20, 81-98.

Waibel, S., Petzold, K., \& Rüger, H. (2018). Occupational status benefits of studying abroad and the role of occupational specificity - A propensity score matching approach. Social Science Research, 74, 45-61.

Wiers-Jenssen, J. (2008). Student mobility and the professional value of higher education from abroad. Oslo: Unipub.

Wiers-Jenssen, J., \& Try, S. (2005). Labour market outcomes of higher education undertaken abroad. Studies in Higher Education, 30(6), 681-705.

Williams.R. (2012). Using the margins command to estimate and interpret adjusted predictions and marginal effects. The Stata Journal, 12(2), 308-331.

Yorke, M. (2006). Employability in higher education: What it is - What it is not. York: The Higher education academy.

Yssaad, L. (2012). The Canadian Immigrant Labour Market. The Immigrant Labour Force Analysis Series, Catalogue no. 71-606-X. Statistics Canada. http://www.statcan.gc.ca/pub/71-606-x/71-606-x2012006-eng.pdf

Publisher's note Springer Nature remains neutral with regard to jurisdictional claims in published maps and institutional affiliations. 